\title{
Note
}

\section{Simultaneous Recovery of Lithium Bromide with Ion Exchange Method}

\author{
Yasuhiro Suzuka, Yukinori Yoshioka, Syouhei Nishihama, and *Kazuharu Yoshizuka \\ Department of Chemical Processes and Environments, Faculty of Environmental Engineering,
}

The University of Kitakyushu, Hibikino 1-1, Kitakyushu 808-0135, Japan

(Manuscript submitted March 31, 2007; accepted June 9, 2007)

\begin{abstract}
The simultaneous recovery of $\mathrm{LiBr}$ from aqueous solution such as seawater and industrial effluent using ion exchange method has been investigated, employing quaternary ammonium salt type adsorbent. The quaternary ammonium salt type adsorbent prepared possesses sufficient adsorption ability for $\mathrm{Br}^{-}$and the adsorption was found to progress with Langmuir mechanism. The selectivity for $\mathrm{Br}^{-}$against $\mathrm{Cl}^{-}$depends on the counter anion of the adsorbent and the adsorbent with counter anion $\mathrm{OH}^{-}$shows the sufficient selectivity for $\mathrm{Br}^{-}$. The $\mathrm{Br}^{-}$ loaded was also eluted by $\mathrm{LiOH}$ from the absorbent to produce $\mathrm{LiBr}$.
\end{abstract}

Key words: recovery, ion exchange, lithium bromide, quaternary ammonium salt type adsorbents

\section{Introduction}

The demands for lithium bromide have been increasing in recent years as a refrigerant for absorption-type chiller and air conditioner. In previous works [1], we have successfully recovered lithium from seawater by using a benchmark plant, employing $\lambda-\mathrm{MnO}_{2}$ adsorbent. In the present work, we attempt to simultaneously recover $\mathrm{LiBr}$ by eluting $\mathrm{Br}^{-}$from the loaded adsorbent with $\mathrm{LiOH}$. We investigated the batchwise adsorption of $\mathrm{Br}^{-}$with quaternary ammonium salt type adsorbent to elucidate the adsorption mechanism and the effect of counter anion of the adsorbent on the selectivity of $\mathrm{Br}^{-}$against $\mathrm{Cl}^{-}$in aqueous solution. In addition, we carried out the column separation of $\mathrm{Br}^{-}$by elution from the loaded adsorbent with $\mathrm{LiOH}$ solution as an elutant.

\section{Experimental}

The quaternary ammonium salt type adsorbent, based on styrene and divinylbenzene co-polymer (OT-K 1020, Muromachi Chemicals), was employed for the adsorbent. The adsorbent was treated twice with $1.0 \mathrm{~mol} / \mathrm{dm}^{3}$ $\mathrm{HCl}, \mathrm{LiOH}$ or $\mathrm{HNO}_{3}$, to obtain $\mathrm{Cl}$ type, $\mathrm{OH}$ type and $\mathrm{NO}_{3}$ type adsorbents, respectively. The aqueous solution was prepared by dissolving $\mathrm{LiBr}$ and/or $\mathrm{LiCl}$ solution to adjust the concentrations of $\mathrm{Br}^{-}$and $\mathrm{Cl}^{-}\left(C_{\mathrm{Br}}=0 \sim 12.5\right.$ $\left.\mathrm{mmol} / \mathrm{dm}^{3}, C_{\mathrm{Br}}=C_{\mathrm{Cl}}=7.5 \mathrm{mmol} / \mathrm{dm}^{3}\right)$. The $\mathrm{pH}$ of aqueous solution was adjusted by adding of $\mathrm{NaOH}$ or $\mathrm{HCl}$ solution ( $\mathrm{pH}=4.0 \sim 12.0$ ). The batchwise adsorption was carried out by shaking the mixture of $20 \mathrm{mg}$ of the adsorbent ( $\mathrm{Cl}$ type, $\mathrm{NO}_{3}$ type, $\mathrm{OH}$ type) and $10 \mathrm{~cm}^{3}$ of the aqueous solution at $298 \mathrm{~K}$ for $2 \mathrm{~h}$. Concentration of each anion in the aqueous solution was measured by ion chromatography (Metrohm 761Compact IC).

The chromatographic operation was carried out using a column packed the adsorbent (wet volume = $\left.0.89 \mathrm{~cm}^{3}\right)$. The aqueous feed solution $\left(C_{\mathrm{Br}}=C_{\mathrm{Cl}}=100 \mathrm{ppm}, \mathrm{pH}=8.0\right)$ was fed upward with $0.39 \mathrm{~cm}^{3} / \mathrm{min}$ to the 
column using a reciprocal pump (UNILOWS uf-7005PSB2). After the break thorough of Br, deionized water was fed to wash out the aqueous feed solution. $\mathrm{LiOH}$ solution of $5 \mathrm{mmol} / \mathrm{dm}^{3}$ was then fed for scrubbing the loaded column. The $\mathrm{Br}^{-}$was then eluted from the loaded adsorbent with $1.0 \mathrm{~mol} / \mathrm{dm}^{3} \mathrm{LiOH}$ solution. The effluent was collected with a fraction collector (Advantec CHF122SA), to measure the concentrations of $\mathrm{Br}^{-}$and $\mathrm{Cl}^{-}$by ion chromatography.

\section{Results and Discussion}

\subsection{Adsorption equilibria of bromide ion}

The adsorption mechanism of $\mathrm{Br}^{-}$with $\mathrm{Cl}$ type adsorbent was revealed to be Langmuir mechanism, and the maximal adsorption amount and equilibrium constant at $\mathrm{pH}_{\mathrm{eq}}=4.9$ were determined as $2.82 \mathrm{mmol} / \mathrm{g}$ and 1.90 $\mathrm{dm}^{3} / \mathrm{mmol}$, respectively. The adsorption behaviors at $\mathrm{pH}_{\mathrm{eq}}=4.9$ with $\mathrm{OH}$ and $\mathrm{NO}_{3}$ types of the adsorbents are quite identical to that with $\mathrm{Cl}$ type adsorbent. Figure 1 shows the effect of $\mathrm{pH}$ on the adsorption amount of $\mathrm{Br}^{-}, q_{\mathrm{Br}}$, from binary $\mathrm{Br}^{-} / \mathrm{Cl}^{-}$aqueous solution, with the various type adsorbent having different counter anions. The $q_{\mathrm{Br}}$ gradually decreases with increasing $\mathrm{pH}$ in aqueous solution in cases of $\mathrm{Cl}$ and $\mathrm{NO}_{3}$ types of the adsorbents. In the case of $\mathrm{OH}$ type adsorbent, the excellent adsorption of $\mathrm{Br}^{-}$was observed in acidic and neutral region $(\mathrm{pH}<7)$, while the adsorption decreased in alkali region $(\mathrm{pH}>8)$. This result indicates that the $\mathrm{OH}$ type adsorbent has the potential for the selective recovery and elution of $\mathrm{Br}^{-}$.

\subsection{Eluted recovery of lithium bromide}

Figure 2 shows the elution profiles of $\mathrm{Br}^{-}$and $\mathrm{Cl}^{-}$from the loaded $\mathrm{OH}$ type adsorbent. $\mathrm{Br}^{-}$was concentrated up to $1600 \mathrm{ppm}$, while $\mathrm{Cl}^{-}$was suppressed to $1200 \mathrm{ppm}$. Since eluted amounts of $\mathrm{Br}^{-}$and $\mathrm{Cl}^{-}$are 1.01 $\mathrm{mmol} / \mathrm{g}$ and $0.62 \mathrm{mmol} / \mathrm{g}$, respectively, the separation ratio of $\mathrm{Br}^{-} / \mathrm{Cl}^{-}, S_{\mathrm{Br} / \mathrm{Cl}}$, was reached to 1.6. In case of corresponding experiments without scrubbing step using diluted $\mathrm{LiOH}$ solution, the $S_{\mathrm{Br} / \mathrm{Cl}}$ was remained close to unity. This enhancement of $S_{\mathrm{Br} / \mathrm{Cl}}$ is due to the scrubbing off of $\mathrm{Cl}^{-}$away from the adsorbent, suggesting the affinity of $\mathrm{Cl}^{-}$to the present adsorbent is possibly lower than $\mathrm{OH}^{-}$.

\section{Acknowledgement}

This work is supported by Grant-in-Aids for the $21 \mathrm{st}$ Century COE Program, for Scientific Research (C), No.18560724 from MEXT, and Salt Science Research Foundation, No. 0707.

\section{References}

1) A. Kitajou, T. Suzuki, S. Nishihama, K. Yoshizuka, Ars Separatoria Acta, 2, 97-106 (2003); A. Kitajou, Y. Suzuka, S. Nishihama, T. Suzuki, K. Yoshizuka, J. Ion Exchange, 16(1), 49-54 (2005)

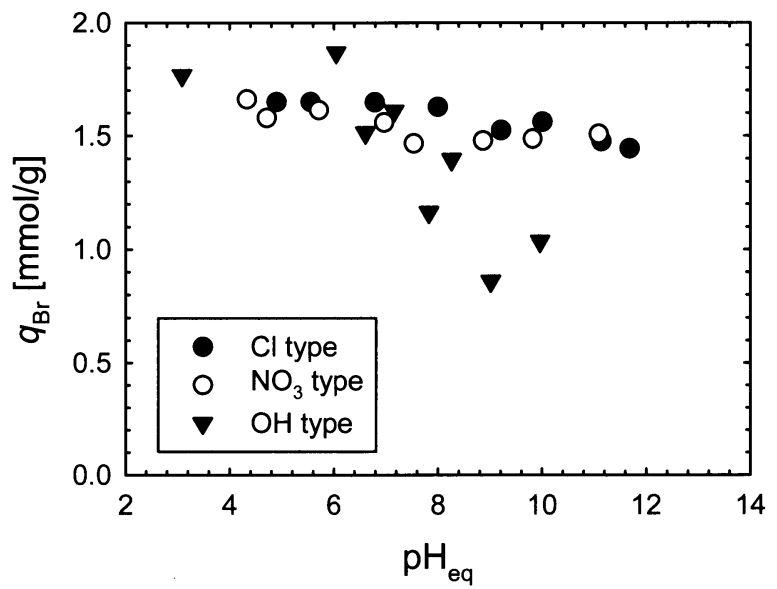

Fig. 1 Effect of $\mathrm{pH}$ on the adsorption amount of $\mathrm{Br}^{-}$using the adsorbent with different counter anion.

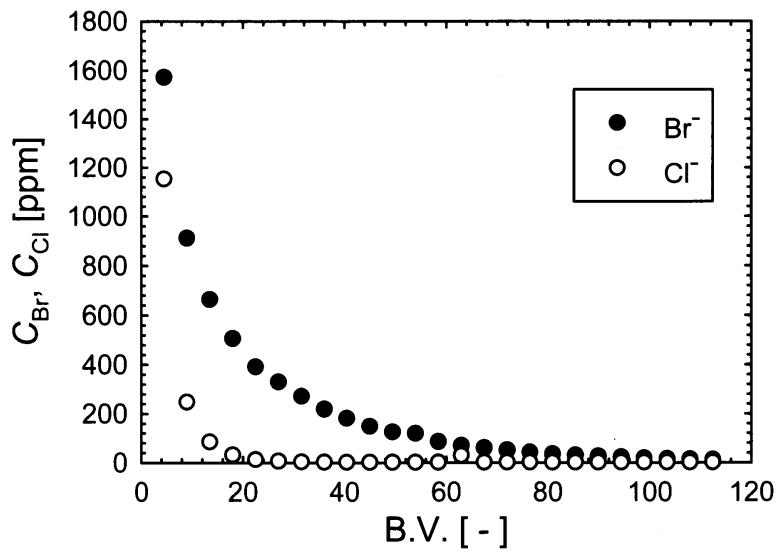

Fig. 2 Elution profiles of $\mathrm{Br}^{-}$and $\mathrm{Cl}^{-}$from the loaded adsorbent. 